\title{
Seropositivity to Non-vaccine Incorporated Genotypes Induced by the Bivalent and Quadrivalent HPV Vaccines: A Systematic Review and Meta-Analysis
}

\author{
Sara L. Bissett, ${ }^{1 \ddagger}$ Anna Godi, ${ }^{1 \ddagger}$ Mark Jit, ${ }^{2,3}$ Simon Beddows ${ }^{1^{*}}$ \\ ${ }^{1}$ Virus Reference Department, Public Health England, London, UK \\ ${ }^{2}$ Modelling and Economics Unit, Public Health England, London, UK \\ ${ }^{3}$ Department of Infectious Disease Epidemiology, Faculty of Epidemiology and Population Health, London \\ School of Hygiene \& Tropical Medicine, London, UK \\ ‡ These authors contributed equally to this study \\ * Corresponding author: Dr. Simon Beddows, Virus Reference Department, Public Health England, 61 \\ Colindale Avenue, London NW9 5EQ, UK. T: +44 (0) 208327 6169. E: simon.beddows@phe.gov.uk
}

Submission to: Vaccine

\section{Figure and Tables:}

Table 1. Summary of studies

Figure 1. Flow chart

Figure 2. Pooled seropositivity estimates

Figure 3. Comparison with VE data

Figure 4. Neutralizing antibody titers

Supplementary Figure. Pooled estimates of Age, timing

\section{Running title (40 chars):}

Non-vaccine type seropositivity

\section{Highlights}

- Evaluation of HPV vaccine seroconversion rates for non-vaccine genotypes

- Pooled estimates for HPV31 and HPV45 higher for bivalent vaccine

- Similar seroconversion rates for HPV33, HPV52 and HPV58

- Estimated seroconversion rates positively associated with vaccine efficacy data 


\begin{abstract}
Background: Human papillomavirus vaccines have demonstrated remarkable efficacy against persistent infection and disease associated with vaccine-incorporated genotypes and a degree of efficacy against some genetically related, non-vaccine-incorporated genotypes. The vaccines differ in the extent of cross-protection against these non-vaccine genotypes. Data supporting the role for neutralizing antibodies as a correlate or surrogate of cross-protection are lacking, as is a robust assessment of the seroconversion rates against these non-vaccine genotypes.

Methods: We performed a systematic review and meta-analysis of available data on vaccineinduced neutralizing antibody seropositivity to non-vaccine incorporated HPV genotypes.

Results: Of 304 articles screened, 9 were included in the analysis representing ca. 700 individuals. The pooled estimate for seropositivity against HPV31 for the bivalent vaccine $(86 \% ; 95 \% \mathrm{Cl} 78-$ $91 \%)$ was higher than that for the quadrivalent vaccine $(61 \% ; 39-79 \% ; p=0.011)$. The pooled estimate for seropositivity against HPV45 for the bivalent vaccine $(50 \% ; 37-64 \%)$ was also higher than that for the quadrivalent vaccine $(16 \% ; 6-36 \% ; p=0.007)$. Seropositivity against HPV33, HPV52 and HPV58 were similar between the vaccines. Mean seropositivity rates across nonvaccine genotypes were positively associated with the corresponding vaccine efficacy data reported from vaccine trials.

Conclusions: These data improve our understanding of vaccine-induced functional antibody specificity against non-vaccine incorporated genotypes and may help to parameterize vaccineimpact models and improve patient management in a post-vaccine setting.
\end{abstract}

\title{
Keywords
}

Human Papillomavirus

Vaccine

Antibody

Systematic review

Meta-analysis 


\section{Introduction}

Human papillomavirus (HPV) is associated with $5 \%$ of all human cancers worldwide and around $30 \%$ of those cancers attributed to infectious agents [1]. The bivalent (Cervarix $®$ ) and quadrivalent (Gardasil®) prophylactic HPV vaccines comprise virus-like particles (VLP) based upon the major capsid protein (L1) of HPV16 and HPV18 [2], which are the two genotypes associated with the majority (ca. 70\%) of cervical cancers [3]. Gardasil® also contains VLP representing genotypes associated with the development of genital warts (HPV6 and HPV11). Both vaccines are highly efficacious at preventing persistent infection and cervical cancer precursors associated with HPV16 and HPV18 in vaccine trials [4-6]. These findings are starting to be reflected in post-licensure impact surveillance data following the implementation of national HPV immunization programmes [7]. Neutralizing antibodies against HPV16 and HPV18 genotypes can be detected in the serum and genital secretions of vaccinees [8], appearing to corroborate pre-clinical animal model data that support type-specific protection being mediated by neutralizing antibodies [9-11].

A degree of cross-protection has also been demonstrated in vaccine trials against persistent infection and disease associated with some non-vaccine genotypes that are genetically related to the vaccine genotypes [4, 12], a phenomenon that is also starting to be seen in vaccinated populations $[7,13]$. The vaccines exhibit differential efficacy in this respect such that Cervarix ${ }^{\circledR}$ appears to be more protective against HPV31 (related to HPV16) than Gardasil囚 and this difference in efficacy is more marked for HPV45 (related to HPV18). These two non-vaccine genotypes alone are associated with ca. $10 \%$ of cervical cancers [3]. Cross-neutralizing antibodies can be detected in the serum and, in one study, the genital secretions of vaccinees [14-20]. These data are derived from relatively small immunogenicity studies, using one or both vaccines and carried out in different age groups, factors that may affect interpretation of whether the detection of such antibodies may be useful as a correlate or surrogate of vaccine-induced cross-protection. This report presents a systematic review and meta-analysis of available data on vaccine-induced neutralizing antibody 
seropositivity to non-vaccine incorporated HPV genotypes in order to provide a robust estimate of seroconversion rates against non-vaccine incorporated genotypes. 


\section{Methods}

\section{Search Strategy and Selection Criteria}

A systematic search was undertaken of PubMed to identify papers reporting seropositivity data in conjunction with cross-neutralizing antibody titers against HPV non-vaccine genotypes. A combination of the following free terms were used to search titles and abstracts: ("HPV" or "Human Papillomavirus") and "Vaccine" and "Antibod" and "Neutrali". Two of the authors (SLB and AG) independently identified papers for analysis that were returned by the search terms up until June 2016. The a priori exclusion criteria were (i) description of a novel antigen, not a licensed HPV vaccine; (ii) description of antibodies elicited by natural infection, not vaccination; (iii) no neutralization data were presented; (iv) no cross-neutralization data were presented in the same or linked study specific paper; (v) not the primary evaluation of study neutralization data. Papers were initially excluded based upon title only, followed by a second round of exclusion based upon abstract content. Where the abstract stated or implied the inclusion of neutralization data within the published study the full text of the paper was reviewed.

\section{Data Extraction}

Key information retrieved for analysis included: participant characteristics (sex, age group), study characteristics (study setting, vaccine(s) used, sample collection times) and assay characteristics (assay format, target antigens, seropositivity, titers). The primary outcome measure was seropositivity to the two oncogenic vaccine incorporated genotypes (HPV16 and HPV18) and five non-vaccine incorporated genotypes (HPV31, HPV33, HPV45, HPV52 and HPV58) for which both efficacy and seropositivity have been consistently evaluated. The secondary outcome measure was the antibody titer to vaccine (HPV16, HPV18) and non-vaccine genotypes (HPV31, HPV45). Two of the authors ( $S B L$ and $A G$ ) performed the data extraction into a template spreadsheet and a data integrity check was performed (SB) before use.

\section{Statistical methods}

Estimates of seropositivity to each genotype following vaccination with either Gardasil $\AA^{\circledR}$ or Cervarix $\AA$ were pooled using a DerSimonian-Laird random effects model, with logit transformed outcome variables. Cochran's Q-test was used as a test of interaction to see if the type of vaccine (or other variable) had a significant impact on seropositivity by genotype.

The association between vaccine efficacy (against persistent infection and CIN2+) as reported from clinical trials [12] and the mean seropositivity generated in this study was investigated. To propagate the uncertainty in these variables to the uncertainty in the linear relationship, we used a resampling technique known as the bootstrap [21]. To do this, we randomly sampled with replacement 1000 
times from the set of positive and negative individuals in the populations of the studies used to estimate efficacy and seroprevalence. Each random sample was then used to construct a related estimate of vaccine efficacy, to construct a set of 1000 bootstrap estimates of vaccine efficacy. This was associated to 1000 similarly constructed estimates of seroprevalence using linear regression.

Vaccine efficacy and seropositivity were plotted on graphs. The uncertainty in the graphs represents the $95 \%$ range of predictions across the models. Exact $95 \%$ confidence intervals for data points were calculated using the Fisher's exact method for vaccine efficacy (1-odds ratio) and ClopperPearson for seroprevalence. Significance was taken at the 5\% level and $95 \%$ confidence intervals used. Two-sided significance tests were used. $R$ version 3.1.2 (R Development Core Team) was used for the analyses.

\section{Results}

We identified 304 articles of which 9 (representing 7 discrete studies) were included for this analysis (Figure 1) [14-20, 22, 23]. Details on the individual studies can be found in Table 1. All studies included females (>95\% of total assessed population) while one study $[18,23]$ also included males. Three studies [14, 16, 19] included adolescent girls at the approximate target age for vaccination (11 - 15 years old) while four studies $[15,17,18,20,22,23]$ included women over 18 years of age. Two studies [16, 19] collected serum from adolescent girls taking part in national vaccination programmes, while five studies $[14,15,17,18,20,22,23]$ collected serum from individuals in the context of a vaccination trial. Post-vaccination seropositivity was assessed at month 7 (1 month post third vaccine dose; M7) [14, 17, 18, 20, 22, 23], month 12 (6 months post third vaccine dose; M12) [14-16, 18, 20, 23], or in one study [19], using data collected between month 7 and month 12. All studies [14-20, 22, 23] evaluated Cervarix $\AA$ vaccinees while five studies [14, 17-20, 22, 23] also included Gardasil® vaccinees. All studies [14-20, 22, 23] used HPV pseudovirus targets HPV16, HPV18, HPV31 and HPV45 in neutralizing antibody tests with five studies [14-16, 18, 20, 23] including one or more additional Alpha-7 (related to HPV18) and Alpha-9 (related to HPV16) genotypes.

Seropositivity against HPV16 and HPV18 was essentially $100 \%$ following three doses of either Cervarix $\AA$ or Gardasil $\AA$ vaccine; a slightly lower (98\%) HPV18 seropositivity was reported by one study following Gardasil $\AA$ vaccination (data not shown). A higher proportion of Cervarix $\circledast$ vaccinees (86\%; 95\% Cl 78 - 91\%; pooled estimate using the random effects model) were seropositive against HPV31 than Gardasil $\AA$ vaccinees $(61 \%$; $39-79 \% ; p=0.011)$ (Figure 2). Cervarix $\AA$ vaccinees (50\%; $37-64 \%$ ) also exhibited a markedly higher proportion of seropositivity against HPV45 than 
Gardasil $\circledast$ vaccinees (16\%; 6 - 36\%; $p=0.007)$. Pooled estimates for seropositivity against HPV33, HPV52 and HPV58 demonstrated no significant difference between the vaccines.

One of these studies $[18,23]$ examined bivalent and quadrivalent vaccine immunogenicity in a cohort of human immunodeficiency virus (HIV-1) infected individuals. Pooled estimates for seropositivity against HPV31 (Cervarix $\AA^{\circ}$ : 87\%; 95\%Cl 78 - 92\%; Gardasil囚: 63\%; 38 - 83\%; p=0.027) and HPV45 (Cervarix®: 47\%; 33 - 62\%; Gardasil®: 11\%; 4 - 28\%; p=0.002) not including these individuals were similar to the overall estimates.

There was a significant positive association between the overall seropositivity rates against nonvaccine incorporated genotypes and the vaccine efficacy data [12] against 6 month persistent infection (mean line coefficient 1.017; 95\% range $0.100-2.241$; Figure 3a) and positive but nonsignificant association with cervical intraepithelial neoplasia grade 2 or greater (CIN2+) (mean line coefficient 1.781 ; $95 \%$ range $-0.636-9.212$; Figure 3 a) reported from vaccine trials.

These immunogenicity studies were carried out in adolescent girls ( $<18$ years old) and adults (18 years or older) and included samples collected between one (M7) and six (M12) months after the third dose of vaccine. There were too few studies to allow a subset analysis, whereby the influence of vaccine, age group, and sampling time on genotype-specific seropositivity could be evaluated independently. Instead, seropositivity to HPV31 or HPV45 was evaluated using age group (irrespective of vaccine and sampling time) and sampling time (irrespective of vaccine and age group) as composite variables (Supplementary figure). This was a similar approach to that taken for the evaluation of seropositivity stratified by vaccine, irrespective of age group and sampling time (Figure 2). The pooled estimate for seropositivity against HPV31 in the adolescent age group (87\%; $71-95 \%)$ was slightly higher than that achieved in adults (66\%; $50-80 \% ; p=0.045)$. Seropositivity against HPV45 for adolescents (31\%; $15-52 \%)$ was similar to that in adults $(38 \% ; 19-61 \%$; $\mathrm{p}=0.613$ ). Overall, seropositivity against HPV31 (M7: 76\%; $57-89 \%$ vs. M12: 81\%; $65-91 \%$; $\mathrm{p}=0.636)$ and HPV45 (M7: 35\%; 19 - 56\% vs. M12: 51\%; 33 - 69\%; 0.268) was similar regardless of sampling time.

The magnitude of the vaccine antibody responses were reported as the median or geometric mean titers for both vaccine (HPV16 and HPV18) and non-vaccine (HPV31 and HPV45) genotypes. Although the magnitude of the titers for both vaccine and non-vaccine genotypes varied widely between studies, the non-vaccine genotype titers appeared to track their respective vaccine-type titers with some consistency (Figure 4). HPV16 titers were a median 170 (inter-quartile range, IQR, 134 - 262) fold higher than HPV31 titers for Cervarix $\circledast$ and a median 337 (201 - 365) fold for 
Gardasil@. HPV18 titers were a median $478(296$ - 1,413) fold higher than HPV45 titers for Cervarix $\AA$ and a median $146(108-1,377)$ fold for Gardasil $\AA$.

\section{Discussion}

We performed a systematic review and meta-analysis of available seropositivity data against nonvaccine genotypes representing seven studies and approximately seven hundred individuals vaccinated with three doses of either Cervarix $\AA$ or Gardasil $\AA$ HPV vaccine [14-20, 22, 23].

The estimated seroconversion rate for neutralizing antibodies against HPV31 was higher than that for HPV45, with Cervarix® vaccinees exhibiting higher rates of seroconversion against both of these genotypes than Gardasil ${ }^{\circledR}$ vaccinees. For HPV33, HPV52 and HPV58 the seroconversion rates were similar between the vaccines. There was a strong association between the seropositivity rates for these non-vaccine genotypes and the efficacy data reported from HPV vaccine trials [24, 25]. HPV31 seropositivity has been shown to be coincident with a reduced risk of HPV31 acquisition post-vaccination with Cervarix ${ }^{\circledR}$, although data supporting a similar relationship for HPV45 and HPV58 were lacking [26].

This review incorporated data from adolescent girls around the target age for vaccination in national immunization programmes and from older women and included data collected between one and six months after the third vaccine dose. Of these variables, only the younger age at vaccination was shown to be associated with a higher seropositivity against HPV31. Where individual studies have compared the immune response to HPV vaccines in populations of similar ages, and using samples collected at the same time point post-vaccination, they have consistently demonstrated higher rates of seroconversion and/or higher titers against both HPV16 and HPV18 [14, 20, 22, 23] and nonvaccine genotypes $[14,17,18,20]$ following Cervarix® vaccination. Similarly, where studies compared serological responses between one and six months following the third vaccine dose, a small decline in seropositivity and/or titers was seen for both adolescents [14] and older women [17, $18,20,22,23]$. The issue of age is more problematic. Only one study in this review examined agedependent immune responses against vaccine and non-vaccine genotypes by stratifying a cohort of 18 - 45 year old mid adult women into three sub-groups (18 - 26, 27 - 35 and 36 - 45 years) and demonstrated some degree of age-related influence on responses against vaccine genotypes [22], but the influence on responses against non-vaccine genotypes was less clear [17]. A stronger serological response elicited in adolescents compared to adult women has been demonstrated for both vaccines [27-30], but only against vaccine-incorporated genotypes using binding assays. The removal of data from one study $[18,23]$ comprising HIV-infected subjects made little difference to the pooled estimates for seropositivity against HPV31 and HPV45 suggesting, based on these 
limited study data, that the HIV serostatus of vaccine recipients may have little impact on HPV vaccine immunogenicity [31].

The magnitude of the neutralizing antibody response varied between studies with responses against non-vaccine genotypes at least two orders of magnitude lower than those elicited against vaccineincorporated genotypes. The long-term durability of cross-neutralizing antibodies is unclear; thus far, antibodies against HPV31 and HPV45 have been detected out to twenty-four months postvaccination $[17,22]$. In the same vaccine comparison study, responses against HPV16 and HPV18 remain robust out to 5 years [32].

There are several shortcomings to this study. The small number of available studies limited a robust evaluation for some non-vaccine genotypes, notably HPV33, HPV52 and HPV58. This is particularly true for estimating seroconversion rates for Gardasil ${ }^{\circledR}$ vaccinees, which were represented by a single study or pair of studies in some cases. The small number of available studies also precluded an analysis of the influence of each variable (vaccine, age group, sampling time) independently. Thus, the differences in seropositivity due to the vaccine may have been confounded by the influence of the age at vaccination and the sampling time post third dose. This confounding likely led to the high heterogeneity scores seen here and potentially obscured more subtle effects of age and sampling time on seropositivity.

This review evaluated studies incorporating a three-dose schedule. Reduced dose arms in vaccine trials have demonstrated non-inferior seropositivity to vaccine genotypes and similar vaccine efficacy [33,34], resulting in a recommendation for a two dose schedule to be adopted worldwide [35]. However, reduced seropositivity to HPV31 has been demonstrated for less than three doses [36], which is likely to be a factor in the reduced vaccine efficacy observed against non-vaccine genotypes HPV31 and HPV45 in a post-hoc analysis of Cervarix® trial data [37]. Nevertheless, this report represents an analysis of the only available functional data with which to evaluate seroconversion rates against non-vaccine incorporated genotypes.

Recently, the nonavalent Gardasil $\circledast 9$ vaccine comprising additional genetically related genotypes HPV31, HPV33, HPV45, HPV52 and HPV58 has demonstrated efficacy in a three dose schedule [38] and non-inferiority of antibody responses for two doses [39]. A nonavalent vaccine has the potential to reduce the incidence of cervical cancer by over $90 \%[3,40]$, is expected to be cost effective [41, 42]. Nonavalent vaccine efficacy against persistent infection or low grade disease associated with any of these additional genotypes in the per protocol population was $\geq 96 \%$ which is considerably higher than any beneficial cross-protective vaccine efficacy induced by either the 
bivalent or quadrivalent vaccines against these genotypes [24, 25, 43]. Although national immunization programmes will likely adopt the nonavalent vaccine in time, to date tens of millions of adolescent girls have been vaccinated with the bivalent or quadrivalent vaccine [44], for which a better understanding of their immunogenic properties including the seroconversion rates, breadth, magnitude and durability of the antibody responses against vaccine and non-vaccine genotypes is warranted.

\section{Contributions}

SLB and AG performed the systematic review. MJ and SB performed the meta-analysis. SB wrote the first draft of the manuscript. All authors contributed to the final version of the manuscript.

\section{Acknowledgements}

We are grateful to Emily Coates and Julie Ledgerwood (Vaccine Research Center, National Institute of Allergy and Infectious Diseases [NIAID], Bethesda, MD) for providing supplemental data for this analysis. We also thank Nicholas Andrews, PHE, for statistical advice.

\section{Conflict of interest statement}

We declare no conflicts of interest.

\section{Funding}

This study received no specific funding. 
Figure 2. Pooled estimates for seroconversion against non-vaccine incorporated genotypes Estimates of seropositivity to each genotype following vaccination with either Gardasilß or Cervarix® pooled using a DerSimonian-Laird random effects model, with logit transformed outcome variables. Test for subgroup differences using Cochran's Q-test.

Figure 3. Comparison of neutralizing antibody seropositivity and reported vaccine efficacy Mean seropositivity data from this meta-analysis, derived using the random effects model are plotted against (a) efficacy against persistent infection and (b) efficacy against CIN2+ reported from trials of Cervarix $\AA$ (blue points) and Gardasil ${ }^{\circledR}$ (red points) vaccinees for each non-vaccine HPV type (HPV31, HPV33, HPV45, HPV52 and HPV58). Vertical error bars represent exact 95\% confidence intervals for the efficacy data, while horizontal error bars represent exact $95 \%$ confidence intervals for the neutralization seropositivity data. The best fitting linear relationship between the two variables (black line) and the 95\% range of bootstrap estimates for this relationship (dotted lines) is also shown. Exact 95\% confidence intervals for data points were calculated using the Fisher's exact method for vaccine efficacy (1-odds ratio) and Clopper-Pearson for seropositivity.

\section{Figure 4. Vaccine and non-vaccine neutralizing antibody titers}

Neutralizing antibody titers against (a) HPV16 (dark shade) and HPV31 (light shade) and (b) HPV18 (dark shade) and HPV45 (light shade) for Cervarix $\AA$ (blue) and Gardasil $\circledast$ (red) vaccinees. First author name and year of publication given for each article with target age group (G, girls <18 years; W, women 18 or more years old) and sampling time (7 or 12 months post first dose; 7+ represents a range from 7-12 months for one study). Data represent the geometric mean $(95 \% \mathrm{Cl})$ neutralizing antibody titers apart from Kemp (2011) and Draper (2011) which represent the median (IQR) neutralizing antibody titers. Size of data points reflect approximate sample sizes in each study.

\section{Supplementary Figure. Pooled estimates for age group and sampling time}

Pooled estimates of seropositivity to (a, c) HPV31 and (b, d) HPV45 stratified by (a, b) age group or (c, d) sampling time following vaccination with either Cervarix ${ }^{\circledR}$ (denoted by an asterisk) or Gardasil $\AA^{\circ}$ using a DerSimonian-Laird random effects model, with logit transformed outcome variables. Test for subgroup differences using Cochran's Q-test. 


\section{References}

[1] de Martel C, Ferlay J, Franceschi S, Vignat J, Bray F, Forman D, Plummer M. Global burden of cancers attributable to infections in 2008: a review and synthetic analysis. Lancet Oncol. 2012;13:607-15.

[2] Schiller JT, Lowy DR. Understanding and learning from the success of prophylactic human papillomavirus vaccines. Nat Rev Microbiol. 2012;10:681-92.

[3] de Sanjose S, Quint WG, Alemany L, Geraets DT, Klaustermeier JE, Lloveras B, Tous S, Felix A, Bravo LE, Shin HR, Vallejos CS, de Ruiz PA, Lima MA, Guimera N, Clavero O, Alejo M, Llombart-Bosch A, ChengYang C, Tatti SA, Kasamatsu E, Iljazovic E, Odida M, Prado R, Seoud M, Grce M, Usubutun A, Jain A, Suarez GA, Lombardi LE, Banjo A, Menendez C, Domingo EJ, Velasco J, Nessa A, Chichareon SC, Qiao YL, Lerma E, Garland SM, Sasagawa T, Ferrera A, Hammouda D, Mariani L, Pelayo A, Steiner I, Oliva E, Meijer CJ, Al-Jassar WF, Cruz E, Wright TC, Puras A, Llave CL, Tzardi M, Agorastos T, Garcia-Barriola V, Clavel C, Ordi J, Andujar M, Castellsague X, Sanchez GI, Nowakowski AM, Bornstein J, Munoz N, Bosch FX. Human papillomavirus genotype attribution in invasive cervical cancer: a retrospective cross-sectional worldwide study. Lancet Oncol. 2010;11:1048-56.

[4] Lehtinen M, Dillner J. Clinical trials of human papillomavirus vaccines and beyond. Nature reviews Clinical oncology. 2013;10:400-10.

[5] Schiller JT, Castellsague X, Garland SM. A review of clinical trials of human papillomavirus prophylactic vaccines. Vaccine. 2012;30 Suppl 5:F123-38.

[6] Di Mario S, Basevi V, Lopalco PL, Balduzzi S, D'Amico R, Magrini N. Are the Two Human Papillomavirus Vaccines Really Similar? A Systematic Review of Available Evidence: Efficacy of the Two Vaccines against HPV. Journal of immunology research. 2015;2015:435141.

[7] Drolet M, Benard E, Boily MC, Ali H, Baandrup L, Bauer H, Beddows S, Brisson J, Brotherton JM, Cummings T, Donovan B, Fairley CK, Flagg EW, Johnson AM, Kahn JA, Kavanagh K, Kjaer SK, Kliewer EV, Lemieux-Mellouki P, Markowitz L, Mboup A, Mesher D, Niccolai L, Oliphant J, Pollock KG, Soldan K, Sonnenberg P, Tabrizi SN, Tanton C, Brisson M. Population-level impact and herd effects following human papillomavirus vaccination programmes: a systematic review and meta-analysis. Lancet Infect Dis. 2015;15:565-80.

[8] Kemp TJ, Garcia-Pineres A, Falk RT, Poncelet S, Dessy F, Giannini SL, Rodriguez AC, Porras C, Herrero R, Hildesheim A, Pinto LA. Evaluation of systemic and mucosal anti-HPV16 and anti-HPV18 antibody responses from vaccinated women. Vaccine. 2008;26:3608-16.

[9] Breitburd F, Kirnbauer R, Hubbert NL, Nonnenmacher B, Trin-Dinh-Desmarquet C, Orth G, Schiller JT, Lowy DR. Immunization with viruslike particles from cottontail rabbit papillomavirus (CRPV) can protect against experimental CRPV infection. J Virol. 1995;69:3959-63.

[10] Suzich JA, Ghim SJ, Palmer-Hill FJ, White WI, Tamura JK, Bell JA, Newsome JA, Jenson AB, Schlegel $R$. Systemic immunization with papillomavirus $L 1$ protein completely prevents the development of viral mucosal papillomas. Proc Natl Acad Sci U S A. 1995;92:11553-7.

[11] Longet S, Schiller JT, Bobst M, Jichlinski P, Nardelli-Haefliger D. A murine genital-challenge model is a sensitive measure of protective antibodies against human papillomavirus infection. J Virol. 2011;85:13253-9.

[12] Malagon T, Drolet M, Boily MC, Franco EL, Jit M, Brisson J, Brisson M. Cross-protective efficacy of two human papillomavirus vaccines: a systematic review and meta-analysis. Lancet Infect Dis. 2012;12:781-9.

[13] Mesher D, Soldan K, Lehtinen M, Beddows S, Brisson M, Brotherton JM, Chow EP, Cummings T, Drolet M, Fairley CK, Garland SM, Kahn JA, Kavanagh K, Markowitz L, Pollock KG, Soderlund-Strand A, Sonnenberg P, Tabrizi SN, Tanton C, Unger E, Thomas SL. Population-Level Effects of Human Papillomavirus Vaccination Programs on Infections with Nonvaccine Genotypes. Emerg Infect Dis. 2016;22:1732-40. 
[14] Draper E, Bissett SL, Howell-Jones R, Waight P, Soldan K, Jit M, Andrews N, Miller E, Beddows S. A randomized, observer-blinded immunogenicity trial of Cervarix $((\mathrm{R}))$ and Gardasil((R)) Human Papillomavirus vaccines in 12-15 year old girls. PLoS One. 2013;8:e61825.

[15] Kemp TJ, Hildesheim A, Safaeian M, Dauner JG, Pan Y, Porras C, Schiller JT, Lowy DR, Herrero R, Pinto LA. HPV16/18 L1 VLP vaccine induces cross-neutralizing antibodies that may mediate cross-protection. Vaccine. 2011;29:2011-4.

[16] Draper E, Bissett SL, Howell-Jones R, Edwards D, Munslow G, Soldan K, Beddows S. Neutralization of non-vaccine human papillomavirus pseudoviruses from the A7 and A9 species groups by bivalent HPV vaccine sera. Vaccine. 2011;29:8585-90.

[17] Einstein MH, Baron M, Levin MJ, Chatterjee A, Fox B, Scholar S, Rosen J, Chakhtoura N, Lebacq M, van der Most R, Moris P, Giannini SL, Schuind A, Datta SK, Descamps D. Comparison of the immunogenicity of the human papillomavirus (HPV)-16/18 vaccine and the HPV-6/11/16/18 vaccine for oncogenic non-vaccine types HPV-31 and HPV-45 in healthy women aged 18-45 years. Hum Vaccin. 2011;7:1359-73.

[18] Toft L, Tolstrup M, Muller M, Sehr P, Bonde J, Storgaard M, Ostergaard L, Sogaard OS. Comparison of the immunogenicity of Cervarix $(R)$ and Gardasil( $R$ ) human papillomavirus vaccines for oncogenic non-vaccine serotypes HPV-31, HPV-33, and HPV-45 in HIV-infected adults. Hum Vaccin Immunother. 2014;10:1147-54.

[19] Barzon L, Squarzon L, Masiero S, Pacenti M, Marcati G, Mantelli B, Gabrielli L, Pascucci MG, Lazzarotto T, Caputo A, Palu G. Neutralizing and cross-neutralizing antibody titres induced by bivalent and quadrivalent human papillomavirus vaccines in the target population of organized vaccination programmes. Vaccine. 2014;32:5357-62.

[20] Herrin DM, Coates EE, Costner PJ, Kemp TJ, Nason MC, Saharia KK, Pan Y, Sarwar UN, Holman L, Yamshchikov G, Koup RA, Pang YY, Seder RA, Schiller JT, Graham BS, Pinto LA, Ledgerwood JE. Comparison of adaptive and innate immune responses induced by licensed vaccines for Human Papillomavirus. Hum Vaccin Immunother. 2014;10:3446-54

[21] Efron B, Tibshirani RJ. An Introduction to the Bootstrap. Monographs on statistics and applied probability 57. 1994;Chapman and Hall/CRC.

[22] Einstein MH, Baron M, Levin MJ, Chatterjee A, Fox B, Scholar S, Rosen J, Chakhtoura N, Meric D, Dessy FJ, Datta SK, Descamps D, Dubin G. Comparative immunogenicity and safety of human papillomavirus (HPV)-16/18 vaccine and HPV-6/11/16/18 vaccine: follow-up from months 12-24 in a Phase III randomized study of healthy women aged 18-45 years. Hum Vaccin. 2011;7:1343-58.

[23] Toft L, Storgaard M, Muller M, Sehr P, Bonde J, Tolstrup M, Ostergaard L, Sogaard OS. Comparison of the immunogenicity and reactogenicity of Cervarix and Gardasil human papillomavirus vaccines in HIVinfected adults: a randomized, double-blind clinical trial. J Infect Dis. 2014;209:1165-73.

[24] Wheeler CM, Castellsague X, Garland SM, Szarewski A, Paavonen J, Naud P, Salmeron J, Chow SN, Apter D, Kitchener H, Teixeira JC, Skinner SR, Jaisamrarn U, Limson G, Romanowski B, Aoki FY, Schwarz TF, Poppe WA, Bosch FX, Harper DM, Huh W, Hardt K, Zahaf T, Descamps D, Struyf F, Dubin G, Lehtinen M. Cross-protective efficacy of HPV-16/18 AS04-adjuvanted vaccine against cervical infection and precancer caused by non-vaccine oncogenic HPV types: 4-year end-of-study analysis of the randomised, double-blind PATRICIA trial. Lancet Oncol. 2012;13:100-10.

[25] Brown DR, Kjaer SK, Sigurdsson K, Iversen OE, Hernandez-Avila M, Wheeler CM, Perez G, Koutsky LA, Tay EH, Garcia P, Ault KA, Garland SM, Leodolter S, Olsson SE, Tang GW, Ferris DG, Paavonen J, Steben M, Bosch FX, Dillner J, Joura EA, Kurman RJ, Majewski S, Munoz N, Myers ER, Villa LL, Taddeo FJ, Roberts C, Tadesse A, Bryan J, Lupinacci LC, Giacoletti KE, Sings HL, James M, Hesley TM, Barr E. The impact of quadrivalent human papillomavirus (HPV; types $6,11,16$, and 18) L1 virus-like particle vaccine on infection and disease due to oncogenic nonvaccine HPV types in generally HPV-naive women aged 16-26 years. J Infect Dis. 2009;199:926-35. 
[26] Safaeian M, Kemp TJ, Pan DY, Porras C, Rodriguez AC, Schiffman M, Cortes B, Katki H, Wacholder S, Schiller JT, Gonzalez P, Penrose K, Lowy DR, Quint W, van Doorn LJ, Herrero R, Hildesheim A, Pinto LA. Cross-protective vaccine efficacy of the bivalent HPV vaccine against HPV31 is associated with humoral immune responses: results from the Costa Rica Vaccine Trial. Hum Vaccin Immunother. 2013;9:1399-406.

[27] Block SL, Nolan T, Sattler C, Barr E, Giacoletti KE, Marchant CD, Castellsague X, Rusche SA, Lukac S, Bryan JT, Cavanaugh PF, Jr., Reisinger KS. Comparison of the immunogenicity and reactogenicity of a prophylactic quadrivalent human papillomavirus (types 6, 11, 16, and 18) L1 virus-like particle vaccine in male and female adolescents and young adult women. Pediatrics. 2006;118:2135-45.

[28] Dobson SR, McNeil S, Dionne M, Dawar M, Ogilvie G, Krajden M, Sauvageau C, Scheifele DW, Kollmann TR, Halperin SA, Langley JM, Bettinger JA, Singer J, Money D, Miller D, Naus M, Marra F, Young E. Immunogenicity of 2 doses of HPV vaccine in younger adolescents vs 3 doses in young women: a randomized clinical trial. Jama. 2013;309:1793-802.

[29] Romanowski B, Schwarz TF, Ferguson LM, Peters K, Dionne M, Schulze K, Ramjattan B, Hillemanns P, Catteau G, Dobbelaere K, Schuind A, Descamps D. Immunogenicity and safety of the HPV-16/18 AS04adjuvanted vaccine administered as a 2-dose schedule compared with the licensed 3-dose schedule: results from a randomized study. Hum Vaccin. 2011;7:1374-86.

[30] Sow PS, Watson-Jones D, Kiviat N, Changalucha J, Mbaye KD, Brown J, Bousso K, Kavishe B, Andreasen A, Toure M, Kapiga S, Mayaud P, Hayes R, Lebacq M, Herazeh M, Thomas F, Descamps D. Safety and immunogenicity of human papillomavirus-16/18 AS04-adjuvanted vaccine: a randomized trial in 10-25-year-old HIV-Seronegative African girls and young women. J Infect Dis. 2013;207:1753-63.

[31] Levin MJ, Huang S, Moscicki AB, Song LY, Read JS, Meyer WA, Saah AJ, Richardson K, Weinberg A. Four-year persistence of type-specific immunity after quadrivalent human papillomavirus vaccination in HIVinfected children: Effect of a fourth dose of vaccine. Vaccine. 2017;35:1712-20.

[32] Einstein MH, Takacs P, Chatterjee A, Sperling RS, Chakhtoura N, Blatter MM, Lalezari J, David MP, Lin L, Struyf F, Dubin G. Comparison of long-term immunogenicity and safety of human papillomavirus (HPV)16/18 AS04-adjuvanted vaccine and HPV-6/11/16/18 vaccine in healthy women aged 18-45 years: end-ofstudy analysis of a Phase III randomized trial. Hum Vaccin Immunother. 2014;10:3435-45.

[33] Toh ZQ, Licciardi PV, Fong J, Garland SM, Tabrizi SN, Russell FM, Mulholland EK. Reduced dose human papillomavirus vaccination: an update of the current state-of-the-art. Vaccine. 2015;33:5042-50.

[34] Basu P, Bhatla N, Ngoma T, Sankaranarayanan R. Less than 3 doses of the HPV vaccine - Review of efficacy against virological and disease end points. Hum Vaccin Immunother. 2016;12:1394-402.

[35] WHO. Meeting of the Strategic Advisory Group of Experts (SAGE) on immunization, April 2014 conclusions and recommendations. Weekly epidemiological record. 2014;89:221 - 36.

[36] Safaeian M, Porras C, Pan Y, Kreimer A, Schiller JT, Gonzalez P, Lowy DR, Wacholder S, Schiffman M, Rodriguez AC, Herrero R, Kemp T, Shelton G, Quint W, van Doorn LJ, Hildesheim A, Pinto LA. Durable antibody responses following one dose of the bivalent human papillomavirus L1 virus-like particle vaccine in the Costa Rica Vaccine Trial. Cancer Prev Res (Phila). 2013;6:1242-50.

[37] Kreimer AR, Struyf F, Del Rosario-Raymundo MR, Hildesheim A, Skinner SR, Wacholder S, Garland SM, Herrero R, David MP, Wheeler CM. Efficacy of fewer than three doses of an HPV-16/18 AS04-adjuvanted vaccine: combined analysis of data from the Costa Rica Vaccine and PATRICIA trials. Lancet Oncol. 2015;16:775-86.

[38] Joura EA, Giuliano AR, Iversen OE, Bouchard C, Mao C, Mehlsen J, Moreira ED, Jr., Ngan Y, Petersen LK, Lazcano-Ponce E, Pitisuttithum P, Restrepo JA, Stuart G, Woelber L, Yang YC, Cuzick J, Garland SM, Huh W, Kjaer SK, Bautista OM, Chan IS, Chen J, Gesser R, Moeller E, Ritter M, Vuocolo S, Luxembourg A. A 9-valent HPV vaccine against infection and intraepithelial neoplasia in women. N Engl J Med. 2015;372:71123. 
[39] Iversen OE, Miranda MJ, Ulied A, Soerdal T, Lazarus E, Chokephaibulkit K, Block SL, Skrivanek A, Nur Azurah AG, Fong SM, Dvorak V, Kim KH, Cestero RM, Berkovitch M, Ceyhan M, Ellison MC, Ritter MA, Yuan SS, DiNubile MJ, Saah AJ, Luxembourg A. Immunogenicity of the 9-Valent HPV Vaccine Using 2-Dose Regimens in Girls and Boys vs a 3-Dose Regimen in Women. Jama. 2016;316:2411-21.

[40] Herrero R, Gonzalez P, Markowitz LE. Present status of human papillomavirus vaccine development and implementation. Lancet Oncol. 2015;16:e206-e16.

[41] Drolet M, Laprise JF, Boily MC, Franco EL, Brisson M. Potential cost-effectiveness of the nonavalent human papillomavirus (HPV) vaccine. Int J Cancer. 2014;134:2264-8.

[42] Brisson M, Laprise JF, Chesson HW, Drolet M, Malagon T, Boily MC, Markowitz LE. Health and Economic Impact of Switching from a 4-Valent to a 9-Valent HPV Vaccination Program in the United States. J Natl Cancer Inst. 2016;108.

[43] Joura E, Bautista O, Luxembourg A. A 9-Valent HPV Vaccine in Women. N Engl J Med. 2015;372:25689.

[44] Bruni L, Diaz M, Barrionuevo-Rosas L, Herrero R, Bray F, Bosch FX, de Sanjose S, Castellsague X. Global estimates of human papillomavirus vaccination coverage by region and income level: a pooled analysis. The Lancet Global health. 2016;4:e453-63. 
Table 1. Study characteristics

\begin{tabular}{|c|c|c|c|c|c|c|c|c|c|c|c|c|}
\hline Author & Year & Sex & $\begin{array}{c}\text { Age } \\
\text { group }^{a}\end{array}$ & $\begin{array}{l}\text { Medical } \\
\text { exclusion } \\
\text { criteria }\end{array}$ & Setting & HPV status & $\begin{array}{l}\text { Vaccines } \\
\text { assessed }\end{array}$ & $\begin{array}{l}\text { Months } \\
\text { post 1st } \\
\text { dose }\end{array}$ & HPV targets & Reporter ${ }^{b}$ & $\begin{array}{c}\text { Assay } \\
\text { threshold }^{c}\end{array}$ & $\begin{array}{c}\text { No. sera per } \\
\text { target }^{\text {Nax }} \\
\left(^{d} \text { Min Max }\right.\end{array}$ \\
\hline Kemp & 2011 & $\mathrm{~F}$ & $18-25$ & Yes & Trial & Unselected & Cervarix® & M12 & $\begin{array}{c}1618314552 \\
58\end{array}$ & seAP & $10(50 \%)$ & 46 \\
\hline Draper & 2011 & $F$ & $13-14$ & No & Programme & Unselected & Cervarix® & M12 & $\begin{array}{c}1618313345 \\
5258\end{array}$ & Luc & $20(80 \%)$ & 69 \\
\hline Einstein & 2011 & $\mathrm{~F}$ & $18-26$ & Yes & Trial & $\begin{array}{c}\text { Seronegative } \\
\text { and DNA } \\
\text { negative }\end{array}$ & $\begin{array}{c}\text { Cervarix® } \\
\text { and } \\
\text { Gardasilß }\end{array}$ & M7 & 16183145 & seAP & $40(50 \%)$ & $103-131$ \\
\hline Draper & 2013 & $\mathrm{~F}$ & $12-15$ & Yes & Trial & Unselected & $\begin{array}{c}\text { Cervarix® } \\
\text { and } \\
\text { Gardasilß }\end{array}$ & M7 \& M12 & $\begin{array}{c}1618313345 \\
5258\end{array}$ & Luc & $20(80 \%)$ & $91-97$ \\
\hline Toft & 2014 & MF & $>18$ & Yes & Trial & $\begin{array}{c}\text { Seronegative } \\
\text { and DNA } \\
\text { negative }\end{array}$ & $\begin{array}{c}\text { Cervarix® } \\
\text { and } \\
\text { Gardasilß }\end{array}$ & M7 \& M12 & 1618313345 & Luc & $40(50 \%)$ & $12-26$ \\
\hline Barzon & 2014 & $\mathrm{~F}$ & $11-13$ & Yes & Programme & Unselected & $\begin{array}{c}\text { Cervarix® } \\
\text { and } \\
\text { Gardasilß }\end{array}$ & M7 - M12 & 16183145 & seAP & $40(50 \%)$ & $50-126$ \\
\hline Herrin & 2015 & $\mathrm{~F}$ & $18-25$ & Yes & Trial & Unselected & $\begin{array}{c}\text { Cervarixß } \\
\text { and } \\
\text { Gardasilß }\end{array}$ & M7 \& M12 & 1618314558 & seAP & $10(50 \%)$ & $7-12$ \\
\hline
\end{tabular}



${ }^{b}$ Assay readout makes use of Luciferase (Luc) or Secreted embryonic alkaline phosphatase (seAP) reporter gene expression

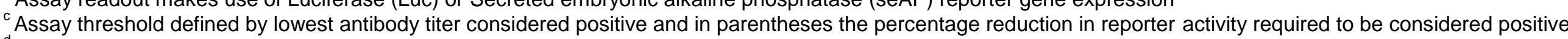

${ }^{\mathrm{d}}$ Number of serum used varies in some studies so numbers are presented as the minimum used (against any target type for any vaccine) to the maximum used. 


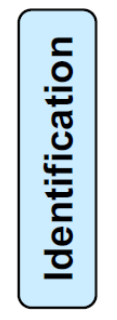

Papers identified through database searching $(n=304)$
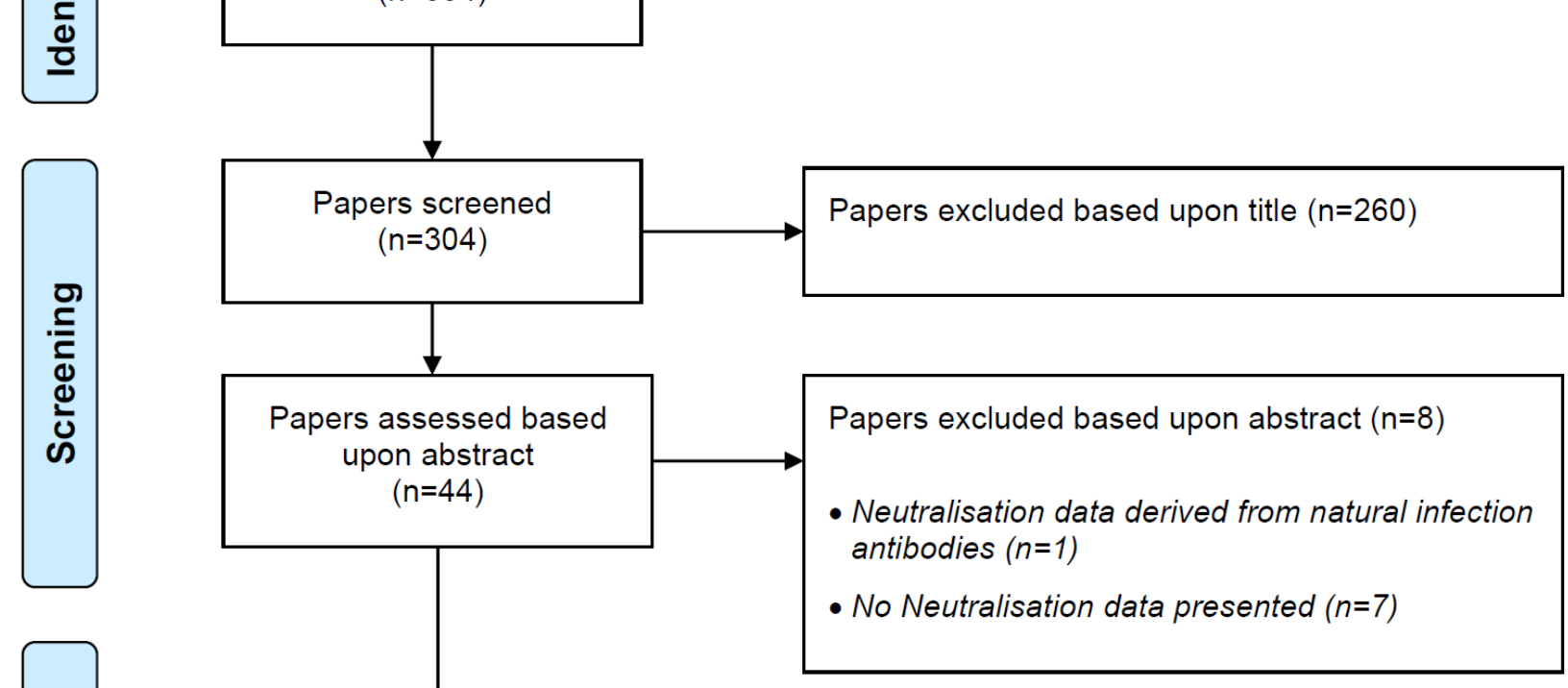

\begin{tabular}{|c|c|}
\hline \multirow{2}{*}{$\begin{array}{l}\text { Full papers assessed for } \\
\text { eligibility } \\
\qquad(\mathrm{n}=36)\end{array}$} & Full papers excluded $(n=27)$ \\
\hline & - Vaccine type neutralisation with no \\
\hline & $\begin{array}{l}\text { - Not the primary presentation of data, manuscript } \\
\text { reproduces a subset of data previously } \\
\text { published }(n=9)\end{array}$ \\
\hline 文 & - Study population pre-selected; not \\
\hline $\begin{array}{l}\text { Papers included in } \\
\text { quantitative synthesis } \\
\text { (meta-analysis) } \\
(\mathrm{n}=9)\end{array}$ & $\begin{array}{l}\text { representative of general population }(n=1) \\
\text { - Neutralisation data presented as an antibody } \\
\text { concentration not as an antibody titre }(n=1)\end{array}$ \\
\hline
\end{tabular}


Figure 2

\section{a) HPV31}

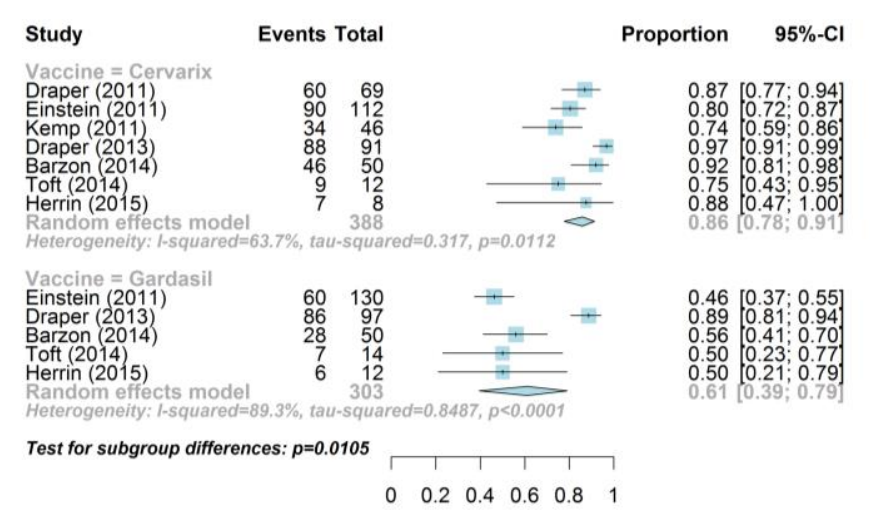

\section{d) HPV52}

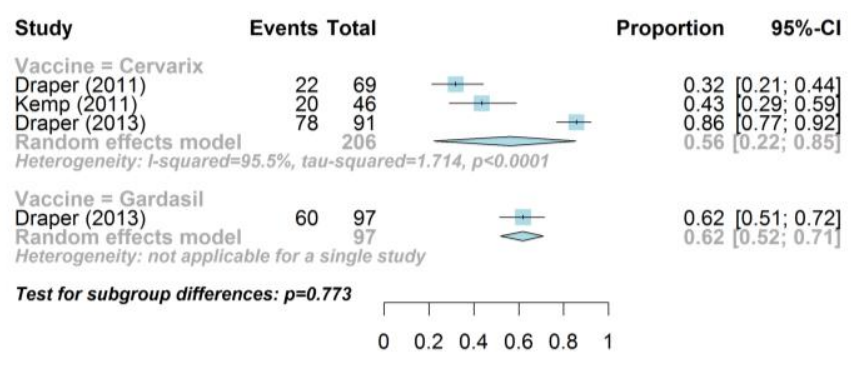

e) HPV58

b) HPV33

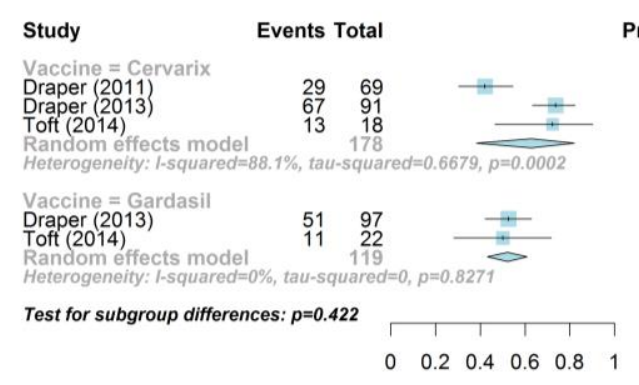

Proportion $\quad 95 \%-\mathrm{Cl}$

$\left.\begin{array}{l}0.42[0.30 ; 0.55 \\ 0.74[0.63 ; 0.82 \\ 0.72[0.47 ; 0.90] \\ 0.63\end{array}\right]$

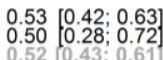

Study

Events Total

Proportion $\quad 95 \%-\mathrm{Cl}$

Vaccine = Cervarix

Kraper (2011)

Draper (2013)

Herrin (2015)

effects model

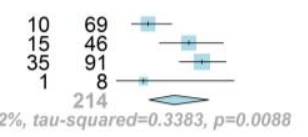

$0.14[0.07 ; 0.25$

$0.380 .28 ; 0.49$

Vaccine $=$ Gardasi

Draper (2013)
Herrin (2015)

Herrin $(2015)$
Random effects model
Heterogeneity: $\mid$-squared $=90.1$

$\begin{array}{rr}19 & 9 \\ 8 & 12\end{array}$

97
12
109

Test for subgroup differences: $p=0.5824$

$\begin{array}{llllll}0 & 0.2 & 0.4 & 0.6 & 0.8 & 1\end{array}$

$0.20[0.12 ; 0.29]$

\section{c) HPV45}

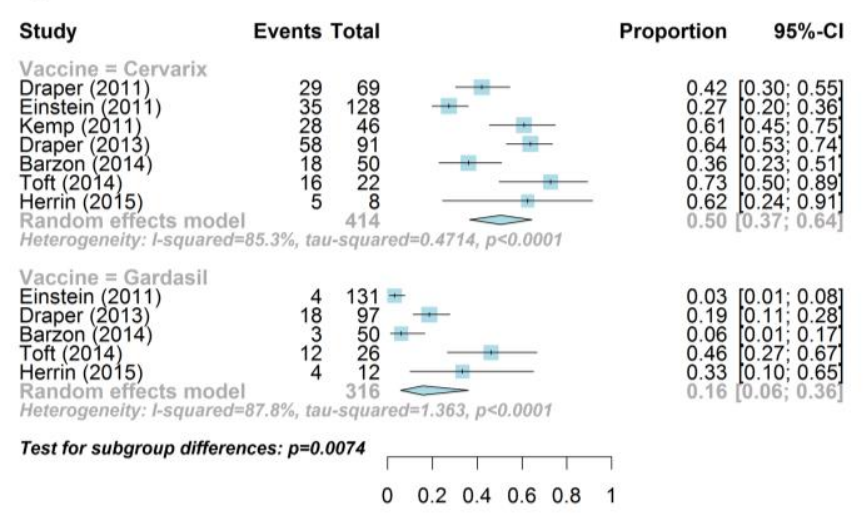


Figure 3

a) Persistent infection



Seroprevalence of neutralizing antibodies b) CIN2+

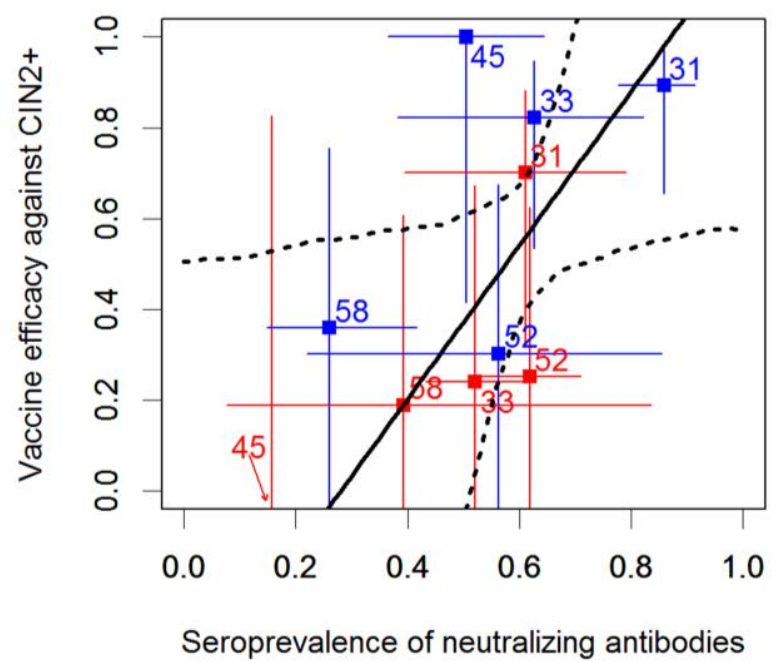


Figure 4

a) HPV16 and HPV31

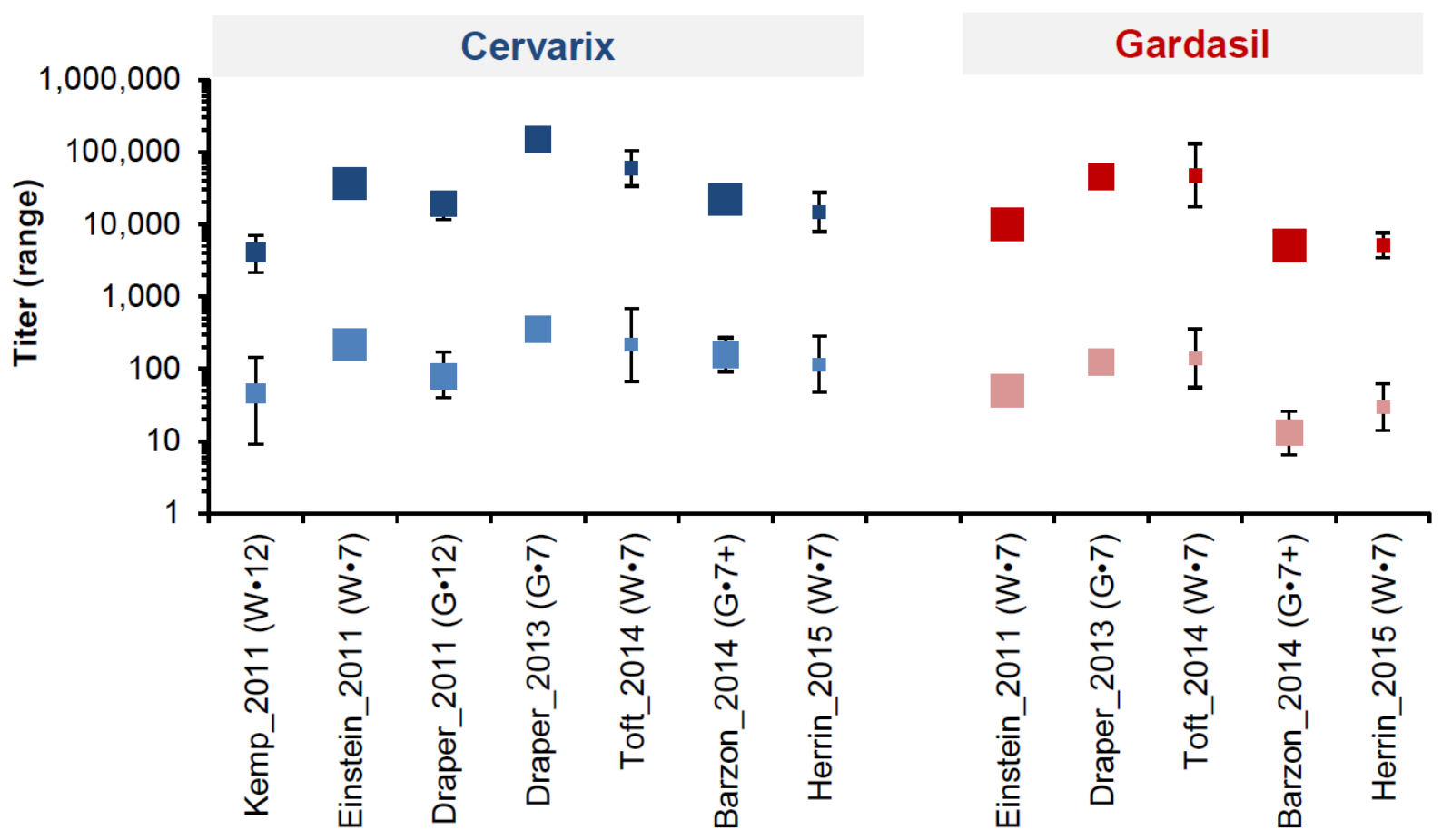

b) HPV18 and HPV45

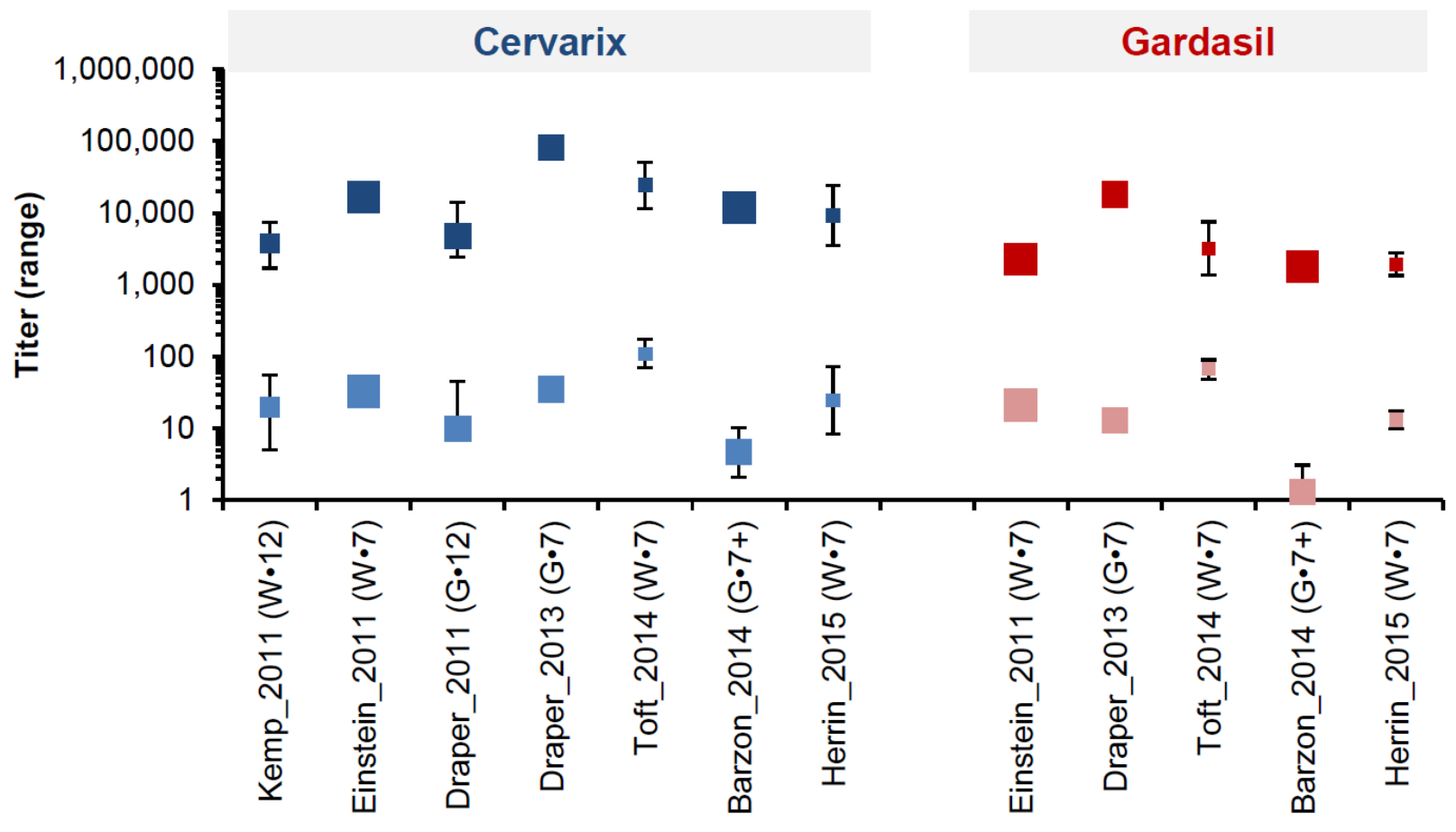




\section{Supplemental Figure}

a) HPV31 Age



b) HPV45 Age

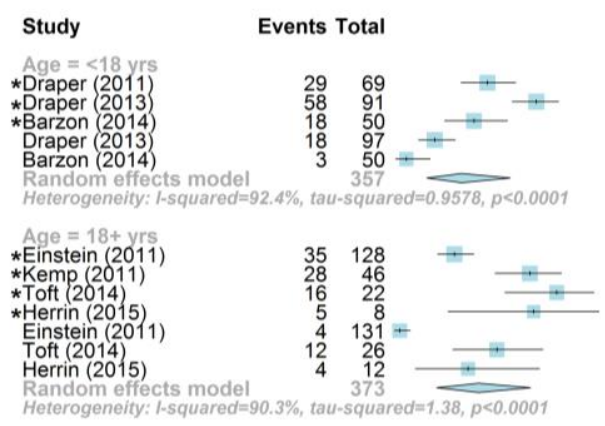

Test for subgroup differences: $p=0.6128$

\section{c) HPV31 Sampling time}

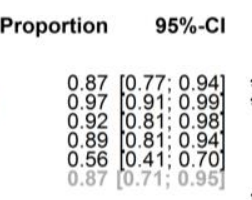

Study

Month = M12

*Draper (2011)

(2011)

Heterogeneity: 1 -squared $=67$.

Month = M7

*Einstein (2011)

* Toft (2014)

*Herrin $(2015)$

Einstein (2011)

Toft (2014)

Herrin (2015)

Heterogeneity: I-squared

Test for subgroup differences: $p=0.6362$

Events Total

$\begin{array}{rr}60 & 69 \\ 34 & 46 \\ & 115\end{array}$

69
46
115



62

Proportion 95\%-C

$0.87\left[\begin{array}{l}0.77 ; 0.94 \\ 0.74\end{array}\right]$

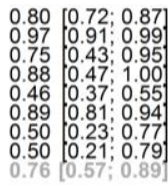

d) HPV45 Sampling time

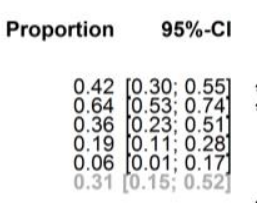

Study

Month $=$ M12

*Draper (2011)

Random effects model

Heterogeneity: $l$-squared $=74.1 \%$, tau-squared $=0.216, \overline{p=0.0493}$

Month = M7

*Einstein (2011)

*Toft (2014)

*Herrin $(2015)$

Einstein (2011)

Toft (2014)

Herrin (2015)

Random effects model

Test for subgroup differences: $p=0.2677$

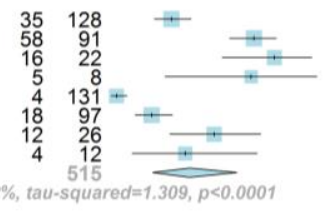

$\begin{array}{llllll}0 & 0.2 & 0.4 & 0.6 & 0.8 & 1\end{array}$
Proportion $\quad 95 \%-\mathrm{Cl}$

$0.42[0.30 ; 0.55$

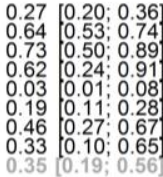

